\title{
Opinions of Undergraduates on the Use of Electronic Examination in a Nigerian University \\ Samuel Oye Bandele [Professor]
}

\author{
sambandele@gmail.com \\ James Ayodele Oluwatayo [Ph.D.] \\ ayotayor@yahoo.com \\ Michael Femi Omodara \\ mfemi87@yahoo.com \\ Faculty of Education, Ekiti State University, Ado-Ekiti, Nigeria
}

Doi:10.5901/mjss.2015.v6n2s1p75

\begin{abstract}
The study investigated opinions of university undergraduates on the use of electronic examination (e-exams). Participants were 600 undergraduates selected from six faculties in Ekiti State University, Ado-Ekiti using stratified random sampling technique. The strata recognised gender (Male $=300$, Female $=300$ ) and faculties (Arts=100, Education=100, Engineering=100, Management Sciences=100, Science=100, Social Sciences=100). Data were collected using a 25-item opinionnaire, each item rated on a four-point scale: Strongly Agree $=4$, Agree $=3$, Disagree $=2$ and Strongly Disagree $=1$, with a reliability coefficient $=0.79$ using Cronbach- $\alpha$ and analysed using means, standard deviations, t-test and one-way ANOVA, tested at 0.05 level of significance. Results showed that the undergraduates favoured the use of e-exams in the university. However, there existed significant variation in opinions of males and females in favour of females while variation in opinions of undergraduates across faculties was insignificant. It was recommended that the university should embrace e-exams and extend same to degree programmes for quality examinations and valid examination results, provide adequate human and material resources for effective operations of e-exams, and prepare the undergraduates electronically to enable them gain proficiency in computer and operation of e-exams for desirable success of the system.
\end{abstract}

Keywords: opinions, undergraduates, use, electronic examination.

\section{Introduction}

Examination is a system of educational measurement designed to obtain information about those who are examined or a process of assessing learning outcome (Obidoa, Onyechi \& Okere, 2013). Valid and reliable examination results have practical utility in education such as certification after completing a course of study (Ogunboyede, 2006), monitoring teaching and learning in schools (Blacks \& William, 1998), diagnosing learning difficulties and selection of prospective candidates for higher training programme (Kolawole, 2014). Examination can take the form of written exercises (created response items or selected response items), oral questions or practical tasks, depending on the attributes being measured.

Over the years, the most recognisable and traditional type of examination in Nigeria has been pencil-and-paper test. This is synonymous to written exercises requiring technical procedures to accomplish. These procedures include test conceptualisation, test construction, test tryouts, test revision, test administration, test scoring and interpretation and reporting examinees' response which take a great deal of time to process (Cohen, Swedlik \& Sturman, 2013). Sadly, the pencil-and-paper examination has been fraught with numerous problems ranging from shortage of examination materials to impersonation, cheating in examination halls, cases of missing scripts, improper scoring of examinees' responses, delay in computing and processing of results, demand for gratification by the lecturers, delay in the issuance of transcript of academic records and so forth (Abdulkareem \& Alabi, 2004; Ekere, 2009).

The disturbing trend in examination fraud in Nigeria tends to show that educational measurement is losing 
credibility, a serious threat to quality educational standard. Fagbamiye (1998) remarked that examination is a powerful educational tool for measuring and judging the standard of education in any country and hardly can a country rise beyond the level of her educational standard except such a country fashions out a dynamic educational system matched with valid and reliable testing programme. In other words, without valid and reliable examination and examination results, there can be no national development either socially, economically, scientifically or technologically. Consequently, there arises a question, if pencil-and-paper examination fails to repose confidence in the test takers and test users, what alternative mode would provide credibility and civility besides validity and reliability?

\section{Literature Review}

In recent years, however, the prospect of assessment or examination via the internet (worldwide web or local area network) seems to be gaining favour with test users (Bartram \& Hambleton, 2006; Terzis \& Economides, 2011). For example, online methodologies have been used to assess interests (Tracey, 2010), problem-solving skills (Mayotte, 2010), admission procedures into Nigerian tertiary institutions (Akpata, 2013). The advantages of electronic examination (e-exams) over pencil-and-paper tests have been documented (Naglieri, Drasgow \& Schmit, 2004; Akpata, 2013; Cohen et al, 2013). Among the advantages cited include (1) test administrators have greater access to potential test users because of the global reach of the internet; (2) scoring and interpretation of test data tend to be quicker than for the pencil-and-paper tests; (3) costs associated with internet testing tend to be lower than the cost associated with penciland-paper tests; (4) the internet facilitates the testing of otherwise isolated population, as well as people with disabilities for whom getting to a test centre might prove a hardship; (5) the system enables educators and trainers to author, schedule, deliver and access reports via World Wide Web (www) or Local Area Network (LAN); (6) e-exams eliminates biased test administration and scoring, increased computer awareness, reduces the spate of examination security and breaches, thus improving the quality and standard of education in the long run. Moreover, e-exams tend to conserve paper and transportation materials. In addition, it reduces cases of impersonation during examinations, reduces delay in compiling and processing of students' results since immediate feedback would be provided, eradicates cases of missing scripts and delay in the processing of transcript of academic records.

Although e-exams appears to have many advantages, it is not totally free from potential problems including cost of establishing facilities, maintenance of hardware and training of personnel to handle examination purposes (Levy \& Ramin, 2007), irregular supply of electricity to power the system and sometimes the loss of internet connectivity (Afolabi \& Abidoye, 2011), the general belief that e-exams is not suitable for all types of examination, especially the extended response items (Doukas \& Andrcatos, 2007), the likelihood of increased anxiety among students with little knowledge of computer operations (Mayotte, 2010), unproctored internet resulting in score inflation (Casrstairs \& Myors, 2010) and the possibility of test takers previewing past and even advanced copies of the tests (Cohen et al, 2013).

Reasonably, the benefits that accrue to students when they are exposed to the possibility of using e-exams require recognition. It is glaring that virtually every aspect of human operation socially, economically, scientifically or technologically, is drifting towards electronic these days and perceptibly, no one would like to be left behind in the vogue. Moreover, the use of e-exams is likely to enhance proficiency in computer operation and provide capability to transform the future of education in Nigeria. The major issue bothers on the undergraduates who are expected to switch from the traditional pencil-and-paper examination to electronic examination. It cannot be assumed that all the students would be motivated to use e-exams. Though Ekiti State University, Ado-Ekiti has successfully used e-exams to conduct the PostUnified Tertiary Matriculation Examination, it has not been extended to undergraduate examinations.

Beyond speculation, e-exams will eventually cover all degree examinations in Nigerian universities based on daily advancement in Information and Communication Technology (ICT) and more importantly, the system has successfully taken off at the National Open University of Nigeria (NOUN), University of llorin, and Rivers State University of Science and Technology, Portharcourt. Against this backdrop, it is expedient to capture the opinions of the undergraduates in Ekiti State Univerity on the use of e-exams, in anticipation of the possibility to use the system. It is assumed that students would recognise the rationale and benefits accruable from e-exams, irrespective of gender diversity and differential faculties.

\section{Purpose of the Study}

The purpose was to investigate opinions of undergraduates in Ekiti State University, Ado-Ekiti on the use of electronic examination and to determine whether undergraduates' gender and differential faculties would influence their opinions on e-exams. 


\section{Research Questions}

The following questions were answered in the study:

1. What opinions do the undergraduates have on the use of e-exams in Ekiti State University, Ado-Ekiti?

2. Does gender influence the opinions of undergraduates on e-exams?

3. Do the undergraduates' differential faculties have any influence on their opinions on e-exams?

\section{Methodology}

\subsection{Research Design}

The research design used in the study was a survey type in order to describe the undergraduates' opinions on the use of e-exams.

\subsection{Sample and Sampling Technique}

The participants were 600 undergraduates selected from six faculties (Arts, Education, Engineering, Management Sciences, Sciences and Social Sciences) using stratified random sampling technique. The stratified recognised gender (Male=300, Female=300) and faculties (100 students per faculty).

\subsection{Research Instrument}

The instrument for collecting data was a self-constructed questionnaire on e-exams, divided into two parts, I and II. Part I was on respondent's biodata including gender (Male/Female) and Faculty. Part II contained 25 items opinionnaire on the use of e-exams, each item rated on a four-point scale; Strongly Agree=4, Agree=3, Disagree=2, Strongly Disagree=1.

\subsection{Validity and Reliability of the Instrument}

The validity procedure of the instrument was ensured by giving copies to experts in Tests and Measurement as well as Science Education who scrutinised the items, corrected and suggested their conformity with the principle of unidimensionality (facing the same direction for easy analysis). Copies of the revised instrument were administered on 50 undergraduates not included in the study and their responses collated and subjected to Cronbach- $\alpha$ to estimate the reliability coefficient of the instrument. The value obtained was 0.79 which was considered high enough for this study.

\subsection{Administration of the Instrument and Data Analysis}

Research assistants were employed to administer the instrument in the various faculties selected. Data collected were analysed using means, standard deviations, t-test and One-Way Analysis of variance (ANOVA) tested at 0.05 level of significance.

The assumption in the analysis was that the ranges of means were defined as follows: 1.00-1.49 (Very Unfavourable), 1.50-2.49 (Unfavourable), 2.50-3.49 (Favourable) and 3.50-4.00 (Very Favourable).

\section{Results}

6.1 Question 1: What opinions do the undergraduates have on the use of electronic examination (e-exams)?

Data were analysed using means and standard deviations (SD) as presented in table 1. 
Table 1: Means and SD on opinions regarding e-exams

\begin{tabular}{|c|c|c|c|c|}
\hline$S / N$ & Statement: Using e-exams will: & Mean & $S D$ & \begin{tabular}{|l|} 
Inter- \\
pretation
\end{tabular} \\
\hline 1. & enhance quality test administration in the University. & 3.51 & 0.37 & Very Favourable \\
\hline 2. & revolutionise education standard in the University. & 2.96 & 0.82 & Favourable \\
\hline 3. & eliminate biased test administration and scoring. & 3.04 & 0.61 & Favourable \\
\hline 4. & improve quality and standard of examination results. & 3.18 & 0.59 & Favourable \\
\hline 5. & enable students recognise the benefits of honesty and hardwork. & 3.01 & 0.74 & Favourable \\
\hline 6. & enable students work independently during examination. & 3.41 & 0.48 & Favourable \\
\hline 7. & reduce anxiety and stress among students. & 2.56 & 0.81 & Favourable \\
\hline 8. & eliminate impersonation through biometric verification. & 3.43 & 0.44 & Favourable \\
\hline 9. & eliminate overcrowding in examination halls. & 3.28 & 0.51 & Favourable \\
\hline 10. & eliminate examination frauds and other unethical behaviours. & 3.40 & 0.41 & Favourable \\
\hline 11. & motivate University to provide basic facilities and regular supply of electricity during examination. & 3.61 & 0.24 & Very Favourable \\
\hline 12. & enable students have access to their results since prompt feedback is provided. & 3.32 & 0.44 & Favourable \\
\hline 13. & enable students monitor their academic progress. & 3.53 & 0.22 & Very Favourable \\
\hline 14. & help to identify students who demonstrate best abilities in various courses. & 3.18 & 0.55 & Favourable \\
\hline 15. & help identify students with learning difficulties. & 3.23 & 0.58 & Favourable \\
\hline 16. & enable students to be computer friendly. & 3.57 & 0.22 & Highly Favourable \\
\hline 17. & prepare students for challenges in ICT. & 3.44 & 0.28 & Favourable \\
\hline 18. & enable each Faculty schedule examination time-table. & 2.94 & 0.67 & Favourable \\
\hline 19. & allow for all types of examination (created or selected response items) to be administered. & 3.07 & 0.64 & Favourable \\
\hline 20. & remove delay in processing students' transcript of academic records. & 3.42 & 0.41 & Favourable \\
\hline 21. & eliminate cases of missing scripts. & 3.63 & 0.24 & Very Favourable \\
\hline 22. & facilitate paperless examination in the University. & 3.42 & 0.56 & Favourable \\
\hline 23. & enable students manage their time effectively during examination. & 3.43 & 0.41 & Favourable \\
\hline 24. & enable students develop strategies for credible performance. & 3.36 & 0.46 & Favourable \\
\hline 25. & improve examination security and reduction in breaches. & 3.47 & 0.51 & Favourable \\
\hline
\end{tabular}

Table 1 shows that the mean scores and deviations of items 1 to 25 were: $3.51(0.37), 2.96(0.82), 3.04(0.61), 3.18(0.59)$, $3.01(0.74), 3.41(0.48), 2.56(0.81), 3.43(0.44), 3.28(0.51), 3.40(0.41), 3.61(0.24), 3.32(0.44), 3.53(0.22), 3.18(055)$, 3.23(0.58), 3.57(0.22), 3.44(0.28), 2.94(0.67), 3.07(0.64), 3.42(0.41), 3.63(0.24), 3.42(0.56), 3.43(0.41), 3.36(0.46) and $3.47(0.51)$ respectively. Deductively, the undergraduates favoured the use of e-exams in the university.

\subsection{Question 2: Does gender of undergraduates influence their opinions on the use of e-exams?}

Data were analysed using t-test comparison as presented in table 2.

Table 2: t-test comparison between opinions of males and females on e-exams

\begin{tabular}{|c|c|c|c|c|c|c|}
\hline Variables & $N$ & Mean & $S D$ & $d f$ & $t_{c a l}$ & $t_{\text {table }}$ \\
\hline Male & 300 & 79.3 & 10.8 & & & \\
\hline Female & 300 & 82.7 & 9.38 & 598 & 4.12 & 3.11 \\
\hline Total & 600 & & & & & \\
\hline
\end{tabular}

Table 2 shows that the mean scores and standard deviations of males and females were 79.3(10.8) and 82.7(9.38) respectively. The t-test calculated was 4.12 while its corresponding table value at 0.05 level of significance was 1.96 . Since t-calculated was greater than t-table, it implies that significant difference existed between the opinions of males and females on e-exams. By comparison, the females had higher mean scores than males signifying that gender had significant influence on opinions of undergraduates on e-exams in favour of females. 
6.3 Question 3: Do the undergraduates' differential faculties have any influence on their opinions on the use of eexams?

Data were analysed using One-Way Analysis of Variance (ANOVA) as presented in table 3.

Table 3: ANOVA Analysis of the performance of the experimental and the control groups in the posttest

\begin{tabular}{|c|c|c|c|c|c|}
\hline Source of Variation & $\mathbf{d f}$ & $\boldsymbol{S S}$ & $\boldsymbol{M S}$ & $\boldsymbol{F}_{\text {cal }}$ & \multirow{2}{*}{$\boldsymbol{F}_{\text {tab }}$} \\
\hline Between group & 5 & 233.6 & 46.71 & & \\
\cline { 1 - 4 } Within group & 594 & 12786.1 & 21.5 & 2.17 & 2.23 \\
\hline Total & 599 & 12969.7 & & & \\
\hline
\end{tabular}

$P>0.05$ (not significant)

Table 3 shows that F-calculated was 2.17 while its corresponding table value at 0.05 level of significance was 2.23 . Since F-calculated was less than F-table, it implies that differential faculties had no significant influence on undergraduates' opinions on the use of e-exams.

\section{Discussion}

The study reported here investigated the opinions of university undergraduates on the use of e-exams. Interestingly, the results in table 1 indicated that the undergraduates favoured the use of e-exams as the mean scores ranged from 2.56 to 3.63. The undergraduates were of the opinions that using e-exams would, among others, enhance quality test administration in the university, motivate university to provide basic facilities and regular supply of electricity during examinations, enable students to be computer friendly, enable students monitor their academic progress and eliminate cases of missing scripts. This tends to fall in line with the global recognition of e-exams as a means of providing credibility and civility to examination system, thus improving the education sector (Akpata, 2013). This also tallies with the finding of Alabi, Issa and Oyekunle (2012) that undergraduates at the University of llorin preferred computer-based testing to pencil-and-paper examination.

The results in table 2 showed that female undergraduates favoured the use of e-exams than their male counterparts. The reason for the difference is not clear. However, it might be attributed to the nature of the instrument resulting into inconsistency in rating or errors of central tendency. Nevertheless, related study by Caspi, Chajut and Saporta (2008) reported that female undergraduates participated in online discussion than males noting that females over-proportionally posted messages on the web-based conference than males.

The results in table 3 showed no significant variation in the opinions of the undergraduates across the selected faculties on the use of e-exams. This is surprising because ordinarily, one would expect significant variation based on the study of Doukas and Andrcatos (2007) that e-exam is not suitable for all types of examinations, especially those involving created response items and rigorous mathematical computations. However, it is glaring that Information and Communication Technology has witnessed unprecedented revolution in the last few years as undergraduates now use internet or mobile phones to respond to questions and assignments. Moreover, some universities in Nigeria (e.g. National Open University of Nigeria, University of Ilorin, Rivers State University of Technology, Portharcourt) have embraced eexams and presumably, the undergraduates in Ekiti State University, Ado-Ekiti might not afford to be left behind irrespective of faculties.

\section{Conclusion}

Based on the findings, it was concluded that undergraduates in Ekiti State University, Ado-Ekiti favoured the use of eexams for quality test administration and educational standard. More importantly, the undergraduates in selected faculties did not differ significantly in their opinions on the use of e-exams which is capable of transforming the future of education in the university.

\section{Recommendations}

Based on the findings and conclusion, the following recommendations were made:

1. Ekiti State University should embrace the use of e-exams and extend same to degree programmes for quality 
examination and valid examination results.

2. The university should provide basic facilities in terms of human and materials for effective and efficient eexams system.

3. The undergraduates should be adequately prepared electronically to enable them gain proficiency in computer operations for desirable success of e-exams.

\section{References}

Abdulkareem, A. Y. \& Alabi, A. T. (2004). Curbing examination malpractice in the university system: A management perspective. Nigerian Journal of Educational Researchers and Evaluators. 5(1): 19-26.

Afolabi, A. F. \& Abidoye, J. A. (2011). The integration of information communication technology in library operations towards effective library services. Proceeding of the 15t International Technology, Education and Environment Conference of African Society for Scientific Research (ASSR). Accessed 29/11/2012. Available online: http://www.bramns.com.

Akpata, A. (2013). CBT: So far, so good. JAMB News. 4(24/25): 4.

Alabi, A. T.; Issa, A. O. \& Oyekunle, R. A. (2012). The use of computer-based testing method for the conduct of examination at the University of llorin. International Journal of Learning and Development. 2(3): 68-80.

Bartram, D. \& Hambleton, R. K. (2006). Computer based testing and the internet: Issues and advances. New York: Wiley.

Black, P. \& Wilian, D. (1998). Assessment and classroom learning. Assessment in Education. 5(1): 7-74.

Casistairs, J. \& Myors, B. (2009). A nature experiment reveals test score inflation on a high stakes unproctored cognitive test. Computers in Human Behaviour. 25: 738-742.

Caspi, A.; Chajut, E. \& Saporta, K. (2008). Participation in class and in online discussions: Gender differences. Journal of Computers and Education. 50(3): 718-724.

Cohen, R. J.; Swerlik, M. E. \& Sturman, E. B. (201'3). Psychological testing and assessment: An introduction to Tests and Measurement; $8^{\text {th }}$ edition. McGraw-Hill. 14-18.

Doukas, N. \& Andrcatos, A. (2007). Advancing electronic assessment. International Journal of Computer Communication and Control. 2(1): 56-65.

Ekere, F. O. (2009). Examination malpractice and the future of Nigerian education system. A paper presented in a symposium organised at Paradele Secondary School, Nsukka. February 19.

Fagbamiye, E. O. (1998). Examination malpractice in Nigeria educational institutions: Is there any hope? In A. Adegboye, O. Olutoye and J. O. Adetunberu (Eds.) Issues on examination malpractice in Nigeria. Ado-Ekiti: PETOA Educational Publishers.

Kolawole, E. B. (2014). Tests and measurement: The panacea to educational evaluation research development in Nigeria. 40 In Inaugural Lecture; Ekiti State University, Ado-Ekiti. Tuesday 26th August.

Levy, Y. \& Ramiu, M. A. (2007). Theoretical approach for biometric authentication of e-examination. Chais Conference on Instructional Technologies Research. Accessed 08/11/2013. Available online: http//klem-pub.openu.com

Majite, S. (2010). Online assessment of problem-solving skills. Computations in Human Behaviour. 26: 1253-1258.

Naglieri, J. A.; Drasgow, F. \& Schmit, M. (2004). Psychological testing on the internet: New problems old issues. American Psychologist. 59: 150-162.

Obidoa, M. A.; Onyechi, K. C. 7 Okere, A. U. (2013). Examination malpractice and control in public secondary schools in Anambra State, Nigeria: Implication for the counsellor. Journal of Education and Practice. 4(28): 69-73.

Ogunboyede, M. O. (2006). Evaluation of the implementation of continuous assessment policy in junior secondary schools in Ondo and Ekiti States. An unpublished Ph.D. thesis submitted to the Faculty of Education, University of Ado-Ekiti, Nigeria.

Terzis, V. \& Economides, A. A. (2011). The acceptance and use of computer-based assessment. Computers and Education. 56: 10321044.

Tracey, T. J. C. (2010). Internet assessment using new technology. Journal of Career Assessment. 18: 336-344. 